\title{
Kecanduan Game Online pada Remaja: Dampak dan Pencegahannya
}

\section{Online Game Addiction in Adolescents: Impacts and its Preventions}

\author{
Eryzal Novrialdy ${ }^{1}$ \\ Prodi S2 Bimbingan dan Konseling, Fakultas Ilmu Pendidikan \\ Universitas Negeri Padang
}

\begin{abstract}
The problem of online game addiction demands public attention. Currently, many studies tend to be focused on efforts to reduce the level of addiction. However, there are very limited studies centered on discussing efforts to prevent this occurrence. This paper aims to examine various alternatives, in order to prevent this form of addiction, especially in adolescents that tend to be the most affected age group. In addition, there have been reports of its impact on several aspects of life, including health, psychologically, academically, socially and financially. Therefore, there is a need for preventive approaches, due to the impacts that disrupt the life of adolescents, which this paper is expected to identify. Furthermore, future research ought to focus on in-depth examination of other alternatives to prevent online game addiction.
\end{abstract}

Keywords: addiction; adolescents; prevention; online game

\begin{abstract}
Abstrak. Kecanduan game online merupakan salah satu masalah yang mendapat perhatian dari masyarakat luas. Saat ini, banyak penelitian yang lebih fokus terhadap upaya untuk mereduksi tingkat kecanduan game online. Namun, masih minim sekali penelitian yang membahas tentang upaya pencegahan kecanduan game online. Tulisan ini bertujuan mengkaji berbagai alternatif untuk mencegah kecanduan game online, terutama terhadap remaja yang mengalaminya. Remaja merupakan kelompok usia terbanyak yang mengalami permasalahan terhadap penggunaan game online. Kecanduan game online pada remaja akan berdampak pada beberapa aspek kehidupan, seperti aspek kesehatan, aspek psikologis, aspek akademik, aspek sosial dan aspek keuangan. Kecanduan game online perlu dicegah karena dampaknya akan membuat kehidupan remaja terganggu. Tulisan ini diharapkan dapat membantu dalam upaya pencegahan kecanduan game online. Lebih lanjut, penelitian di masa yang mendatang perlu untuk mengkaji secara mendalam berbagai alternatif lain dari pencegahan kecanduan game online.
\end{abstract}

Kata kunci: game online; pencegahan; kecanduan; remaja

\section{Pengantar}

Remaja berada pada rentang usia 12-18 tahun (Hurlock, 2010). Masa remaja merupakan masa peralihan dari anak-anak

\footnotetext{
${ }^{1}$ Korespondensi mengenai artikel ini dapat melalui: erynvrld@gmail.com
}

menuju dewasa (Santrock, 2007). Pada masa ini remaja akan sangat mengalami berbagai perubahan pada dirinya, baik itu dari fisik maupun psikis, secara individual ataupun dalam peran sosialnya di keluarga, sekolah serta masyarakat. Remaja yang tumbuh dan berkembang 
pada era milenium saat ini akan bersinggungan dengan banyaknya kecanggihan teknologi yang memudahkan untuk memperoleh berbagai informasi yang dibutuhkannya (Novrialdy, Nirwana, \& Ahmad, 2019). Menurut Oblinger \& Oblinger (2005) remaja saat ini dapat disebut generasi post-millenials. Salah satu cirinya yaitu tumbuh dengan teknologi yang sangat mudah untuk diaksesnya, sehingga hal tersebut membuat remaja saat ini dapat juga dikatakan sebagai generasi yang paling memahami teknologi (Novrialdy, Nirwana, \& Ahmad, 2019).

Kemudahan akses ini akan dapat berdampak buruk jika tidak disikapi dengan baik. Hasil penelitian menunjukkan bahwa remaja merupakan kelompok usia terbanyak yang mengalami permasalahan dengan penggunaan teknologi, seperti internet (Kuss, van Rooij, Shorter, Griffiths, \& van de Mheen, 2013; Tsitsika et al., 2014), smartphone (Haug et al., 2015; Cha \& Seo, 2018) dan game online (Hussain, Griffiths, \& Baguley, 2012; Jiang, 2014; Király et al., 2014; Strittmatter et al., 2015; Wang et al., 2014).

Permasalahan yang terkait dengan penggunaan game online telah mendapat banyak perhatian dari masyarakat luas. Game online adalah permainan yang dapat dimainkan oleh banyak orang pada waktu bersamaan melalui jaringan internet (Adams, 2013). Sejak kemunculannya game online menjadi sangat populer dan mudah untuk diakses. Game online dapat dimainkan di berbagai platform, seperti komputer pribadi (PC), konsol game (alat khusus untuk bermain game) dan smartphone (Kiraly, Nagygyörgy, Griffiths, \& Demetrovics, 2014). Saat ini, game online seperti Mobile Legend (ML), Arena of Valor (AoV), Clash of Clans (CoC), Fortnite, Dota 2 dan Player Unknown's Battle Ground (PUBG) merupakan salah satu kegiatan rekreasi yang paling luas terlepas dari budaya, usia, dan jenis kelamin.

Game online akan berdampak positif apabila dimanfaatkan untuk hiburan (Adams, 2013), di mana segala rasa penat dan stres dapat dikurangi dengan bermain game (Russoniello, O'Brien, \& Parks, 2009). Namun yang terjadi saat ini, game online banyak dimainkan secara berlebihan dan digunakan sebagai tempat untuk melarikan diri dari realitas kehidupan sehingga yang terjadi adalah kecanduan game online (Hussain \& Griffiths, 2009).

Remaja dianggap lebih sering dan lebih rentan terhadap kecanduan game online daripada orang dewasa. Masa remaja yang berada pada periode ketidakstabilan, cenderung lebih mudah terjerumus terhadap percobaan hal-hal baru (Jordan \& Andersen, 2016). Masa remaja juga lekat dengan stereotype periode bermasalah (Hurlock, 2010), yang memungkinkan percobaan terhadap hal baru tersebut berisiko menjadi perilaku bermasalah. Akibatnya, remaja yang kecanduan game online cenderung kurang tertarik terhadap kegiatan lain, merasa gelisah saat tidak dapat bermain game online (Jannah, Mudjiran, \& Nirwana, 2015), penurunan prestasi akademik, relasi sosial, dan kesehatan (Ghuman \& Griffiths, 2012). Sebagai contoh, seorang remaja asal Taiwan meregang nyawa setelah bermain game online selama 40 jam tanpa henti (Rania, 2018). Di Indonesia sendiri, 10 anak di Banyumas didiagnosis mengalami gangguan mental akibat kecanduan game online dan harus mendapat terapi di RSUD Banyumas (Aziz, 2018).

Kecanduan game online dapat memberikan dampak buruk terhadap remaja. Sehingga diperlukan upaya agar remaja dapat terhindar dari kecanduan game online. Telah banyak penelitian yang 
dilakukan tentang kecanduan game online. Namun dari banyaknya penelitian tersebut, masih sedikit sekali penelitian yang lebih fokus terhadap upaya pencegahan kecanduan game online. Dalam artikel ini, penulis mencoba untuk meninjau dampak dan upaya pencegahan yang dapat dilakukan untuk permasalahan kecanduan game online.

\section{Pembahasan}

\section{Kecanduan Game Online pada Remaja}

Kardefelt-Winther (2017) menjelaskan bahwa pada awalnya kecanduan hanya berkaitan dengan zat adiktif (contohnya alkohol, tembakau, dan obat-obatan terlarang) yang masuk melewati darah dan menuju ke otak dan dapat merubah komposisi kimia otak. Namun, saat ini konsep kecanduan telah berkembang (Alexander, 2010; Peele, 2004). Istilah kecanduan berkembang seiring dengan perkembangan kehidupan masyarakat, sehingga istilah kecanduan tidak hanya melekat pada obat-obatan tetapi dapat juga melekat pada kegiatan atau suatu hal tertentu yang dapat membuat seseorang ketergantungan, baik secara fisik atau psikologis.

World Health Organization (2018) mendefinisikan kecanduan game online sebagai gangguan mental yang dimasukkan ke dalam International Classification of Diseases (ICD-11). Hal ini ditandai dengan gangguan kontrol atas game dengan meningkatnya prioritas yang diberikan pada game lebih dari kegiatan lain. Perila$\mathrm{ku}$ tersebut terus dilanjutkan walaupun memberikan konsekuensi negatif pada dirinya. Sebuah studi menunjukkan bahwa kecanduan game online lebih sering terjadi pada remaja (Brand, Todhunter, \& Jervis, 2017). Kecanduan game online yang dialami remaja akan sangat banyak meng- habiskan waktunya. Remaja menghabiskan waktu saat bermain game lebih dari dua jam/hari, atau lebih dari 14 jam/minggu (Rudhiati, Apriany, \& Hardianti, 2015) bahkan 55 jam dalam seminggu (van Rooij, Schoenmakers, Vermulst, van den Eijnden, \& van de Mheen, 2011) atau rata-rata 20-25 jam dalam seminggu (Chou, Condron, \& Belland, 2005).

Penelitian yang dilakukan Jap, Tiatri, Jaya, \& Suteja (2013) mengungkapkan bahwa $10,15 \%$ remaja di Indonesia terindikasi mengalami kecanduan game online. Artinya, 1 dari 10 remaja di Indonesia terindikasi mengalami kecanduan game online. Fenomena kecanduan game online ini semakin meluas dan semakin memprihatinkan, terutama karena banyaknya remaja yang menjadi pecandu game online.

Dampak Kecanduan Game Online pada Remaja

Ghuman \& Griffiths (2012) menjelaskan ada masalah yang timbul dari aktivitas bermain game online yang berlebihan, di antaranya kurang peduli terhadap kegiatan sosial, kehilangan kontrol atas waktu, menurunnya prestasi akademik, relasi sosial, finansial, kesehatan, dan fungsi kehidupan lain yang penting. Bahaya utama yang ditimbulkan akibat kecanduan game online adalah investasi waktu ekstrem dalam bermain (Baggio et al., 2016). Penggunaan waktu yang berlebihan untuk bermain game online membuat terganggunya kehidupan seharihari. Gangguan ini secara nyata mengubah prioritas remaja, yang menghasilkan minat sangat rendah terhadap sesuatu yang tidak terkait game online (King \& Delfabbro, 2018). Remaja yang kecanduan game online semakin tidak mampu untuk mengatur waktu bermain. Akibatnya, 
remaja mengabaikan dunia nyata dan peran di dalamnya.

Kecanduan game online dapat memberikan dampak negatif atau bahaya bagi remaja yang mengalaminya. Dampak yang akan muncul akibat kecanduan game online meliputi lima aspek, antara lain aspek kesehatan, aspek psikologis, aspek akademik, aspek sosial, dan aspek keuangan (King \& Delfabbro, 2018; (King \& Delfabbro, 2018: Sandy \& Hidayat, 2019).

Aspek kesehatan. Kecanduan game online mengakibatkan kesehatan remaja menurun. Remaja yang kecanduan game online memiliki daya tahan tubuh yang lemah akibat kurangnya aktivitas fisik, kurang waktu tidur, dan sering terlambat makan (Männikkö, Billieux, \& Kääriäinen, 2015).

Aspek psikologis. Banyaknya adegan game online yang memperlihatkan tindakan kriminal dan kekerasan, seperti: perkelahian, perusakan, dan pembunuhan secara tidak langsung telah memengaruhi alam bawah sadar remaja bahwa kehidupan nyata ini adalah layaknya sama seperti di dalam game online tersebut. Ciriciri remaja yang mengalami gangguan mental akibat pengaruh game online, yakni mudah marah, emosional, dan mudah mengucapkan kata-kata kotor (Petrides \& Furnham, 2000).

Aspek akademik. Usia remaja berada pada usia sekolah yang memiliki peran sebagai siswa di sekolah. Kecanduan game online dapat membuat performa akademiknya menurun (Lee, Yu, \& Lin, 2007). Waktu luang yang seharusnya sangat ideal untuk mempelajari pelajaran di sekolah justru lebih sering digunakan untuk menyelesaikan misi dalam game online. Daya konsentrasi remaja pada umumnya terganggu sehingga kemampuan dalam menyerap pelajaran yang disampaikan guru tidak maksimal.
Aspek sosial. Beberapa gamer merasa menemukan jati dirinya ketika bermain game online melalui keterikatan emosional dalam pembentukan avatar, yang menyebabkannya tenggelam dalam dunia fantasi yang diciptakannya sendiri. Hal ini dapat membuat kehilangan kontak dengan dunia nyata sehingga dapat menyebabkan berkurangnya interaksi (Marcovitz, 2012). Meskipun ditemukan bahwa terjadi peningkatan sosialisasi secara online namun di saat yang sama juga ditemukan penurunan sosialisasi di kehidupan nyata (Williams, 2006; Smyth, 2007; Hussain \& Griffiths, 2009). Remaja yang terbiasa hidup di dunia maya, umumnya kesulitan ketika harus bersosialisasi di dunia nyata. Sikap antisosial, tidak memiliki keinginan untuk berbaur dengan masyarakat, keluarga dan juga teman-teman adalah ciri-ciri yang ditunjukkan remaja yang kecanduan game online (Sandy \& Hidayat, 2019).

Aspek keuangan. Bermain game online terkadang membutuhkan biaya, untuk membeli voucher saja supaya tetap bisa memainkan salah satu jenis game online dibutuhkan biaya yang tidak sedikit. Remaja yang belum memiliki penghasilan sendiri dapat melakukan kebohongan (kepada orang tuanya) serta melakukan berbagai cara termasuk pencurian agar dapat memainkan game online. Hal ini sesuai dengan hasil penelitian Chen et al. (2005) yang menemukan bahwa mayoritas kejahatan game online ialah pencurian $(73,7 \%)$ dan penipuan $(20,2 \%)$. Penelitian ini juga menemukan bahwa usia pelaku kejahatan akibat game online adalah remaja usia sekolah.

\section{Upaya Pencegahan Kecanduan Game Online} pada Remaja

Pencegahan adalah istilah yang merujuk kepada beragam intervensi yang bertujuan 
menghalangi dan menghindari kondisi yang berisiko bermasalah ( $\mathrm{O}^{\prime}$ Connell, Boat, \& Warner, 2009). Menurut Romano \& Hage (2000) pencegahan mencakup berbagai upaya diantaranya: (a) menghentikan perilaku bermasalah sebelum terjadi; (b) menunda timbulnya perilaku masalah; (c) mengurangi dampak dari masalah perilaku dan (d) memperkuat pengetahuan, sikap, dan mempromosikan perilaku positif. Beberapa upaya pencegahan kecanduan game online antara lain attention switching, dissuasion, education, parental monitoring dan resource restriction (Xu, Turel, \& Yuan, 2012).

Attention switching adalah kegiatan yang dilakukan untuk mengalihkan perhatian pemain dari keterlibatan yang berlebihan terhadap game online ( $\mathrm{Xu}$ \& Yuan, 2008; Xu et al., 2012). Attention switching memiliki pengaruh yang signifikan terhadap penurunan dan pencegahan dampak negatif pada kecanduan game online ( $\mathrm{Xu} \&$ Yuan, 2008). Kegiatan ekstrakurikuler seperti olahraga dapat membuat remaja tidak terlalu fokus pada game online dan dapat mengurangi tingkat bermain serta pada akhirnya mengurangi tingkat kecanduan game online ( $\mathrm{Xu}$ et al., 2012). Untuk itu, penting bagi orang yang berada di sekitar remaja (significant others) memahami potensi, bakat, maupun minat dalam hal pengalihan perhatian dalam mencegah kecanduan game online.

Dissuasion adalah tindakan yang dilakukan untuk mencegah bermain game online dengan cara memberikan nasihat, argumen, membujuk, menjelajahi sampai dalam bentuk paksaan (Xu \& Yuan, 2008; $\mathrm{Xu}$ et al., 2012). Istilah ini erat kaitan tindakan persuasif. Hal ini merupakan sebuah praktik umum yang dilakukan oleh kekuatan eksternal (regulator, orang tua, guru, dan teman) untuk pencegahan perilaku yang tidak diinginkan (Xu et al.,
2012). Penelitian yang dilakukan Babor menunjukkan bahwa tindakan persuasif dapat membuat perbedaan, setidaknya dalam kasus penyalahgunaan alkohol (Xu et al., 2012). Seperti yang diketahui bahwa para pecandu game online memiliki rasionalitas terdistorsi (Zhou, Yuan, \& Yao, 2012) dan persuasi adalah salah satu cara potensial untuk membentuk dan menjadi counter terhadap rasionalitas yang terdistorsi.

Education mengacu pada pengetahuan atau fokus upaya pendidikan yang bertujuan pada kognisi seseorang ( $\mathrm{Xu}$ et al., 2012). Sebagai lawan dari dissuasion yang merupakan upaya aktif melawan yang ada pada ranah kognitif seseorang, education sebagian besar ditujukan untuk membangun dasar kognitif yang baik dan dapat dikelola sendiri ( $\mathrm{Xu}$ et al., 2012). Artinya, individu harus aktif dalam memastikan dirinya agar terhindar dari kecanduan game online (misalnya, dengan membaca artikel surat kabar atau menonton berita TV tentang topik tersebut). Selain itu, dibutuhkan juga dorongan dari lingkaran sosial agar upaya ini dapat berjalan dengan baik. Sekolah sebagai sarana pendidikan dapat memberikan bantuan dari upaya tersebut. Sekolah dapat melakukan intervensi dengan mempromosikan perilaku positif sebagai bentuk pencegahan kecanduan game online. Remaja yang masih dalam usia sekolah bisa mendapatkan pengetahuan dan pemahaman yang baik di sekolah. Upaya yang dilakukan sekolah untuk mencegah perilaku kecanduan merupakan upaya yang efektif dan efisien (Griffin \& Botvin, 2010; Wells, Barlow, \& StewartBrown, 2003).

Berdasarkan hasil penelitian Novrialdy, Nirwana, \& Ahmad (2019) ditemukan bahwa masih banyak remaja yang belum memiliki pemahaman yang 
memadai mengenai bahaya kecanduan game online. Pemahaman bahaya kecanduan game online penting bagi remaja karena hal ini bisa menjadi bahan pertimbangan dalam pengambilan keputusan ketika bermain game online. Untuk itu, remaja perlu ditingkatkan pemahamannya mengenai bahaya kecanduan game online. Upaya ini perlu dipertimbangkan sebagai langkah awal dari pencegahan kecanduan game online.

Parental monitoring adalah upaya yang dilakukan orang tua dalam memperhatikan anaknya ( $\mathrm{Xu}$ et al., 2012). Orang tua memegang peranan penting dalam pencegahan perilaku bermasalah remaja (Chen, Grube, Nygaard, \& Miller, 2008), terutama kecanduan (MogroWilson, 2008; Loke \& Wong, 2010). Studi yang dilakukan van den Eijnden, Spijkerman, Vermulst, van Rooij, \& Engels (2010) memberikan bukti bahwa komunikasi orang tua tentang penggunaan internet merupakan cara yang efektif untuk mencegah kecanduan internet. Hal ini bisa menjadi indikasi bagaimana perlunya jalinan komunikasi yang baik antara orang tua dan anaknya.

Kurangnya pengawasan orang tua berkorelasi dengan perilaku berisiko yang mengarah pada perilaku antisosial dan penggunaan zat terlarang pada remaja (Dishion, Nelson, \& Kavanagh, 2003; Kiesner, Dishion, Poulin, \& Pastore, 2009). Kwon, Chung, \& Lee (2011) mengungkapkan bahwa remaja cenderung untuk meningkatkan waktu yang dihabiskan untuk permainan internet saat merasa memiliki hubungan yang buruk dengan orang tuanya. Pemantauan dalam hal game online merupakan strategi efektif yang mencegah pengguna untuk terlibat tindakan penggunaan berlebihan atau tidak tepat (Young, 1998). Orang tua harus berhati-hati dan penuh pertimbangan dalam memberikan akses terhadap berbagai produk teknologi. Para orang tua harus lebih mengawasi anak-anaknya dalam bermain game online karena bisa berpotensi membuat anak-anak menjadi kecanduan bermain game online. Bagi anak-anak yang kecanduan game online, mereka seolah-olah menganggap masa depannya ada di dunia game sehingga menurunkan minat terhadap aktivitas lain. Pemantauan orang tua dapat dilakukan dengan menjalin komunikasi yang baik dengan anak, menempatkan berbagai produk teknologi di tempat yang mudah diamati, mengetahui keberadaan anak, menunjukkan perhatian terhadap kegiatan sekolah anak, dll. Hal tersebut dapat mengurangi waktu anak dalam bermain game online dan mencegah tingkat kecanduan game online yang lebih parah.

Resource restriction adalah pembatasan berbagai sumber daya untuk bermain game online ( $\mathrm{Xu}$ et al., 2012). Kecanduan game online dapat disebabkan oleh berbagai faktor. Salah satu faktor yang menyebabkan kecanduan game online adalah mudahnya akses untuk bermain game online (King, Delfabbro, Zwaans, \& Kaptsis, 2014). Menurut King \& Delfabbro (2018) individu yang memiliki kemudahan akses untuk bermain game online, cenderung akan bermain lebih sering dan lebih lama. Remaja yang memiliki akses perangkat media elektronik di kamar tidur cenderung akan tidur lebih larut, memiliki durasi waktu tidur lebih singkat dan kurang konsentrasi melakukan kegiatan pada siang harinya (Brunborg et al., 2011; Fossum, Nordnes, Storemark, Bjorvatn, \& Pallesen, 2014; Li et al., 2007; Oka, Suzuki, \& Inoue, 2008; Punamäki, Wallenius, Nygård, Saarni, \& Rimpelä, 2007; Shochat, Flint-Bretler, \& Tzischinsky, 2010).

Penelitian terbaru yang dilakukan Gentile et al. (2017) mengungkapkan bah- 
wa remaja yang memiliki media elektronik kamar tidur lebih cenderung menggunakannya untuk bermain game daripada membaca buku. Persepsi individu tentang ketersediaan sumber daya (misalnya, dukungan teknis) memengaruhi penggunaannya sistem informasi (Taylor \& Todd, 1995). Hal ini pun juga berlaku untuk game online (Blakely, Skirton, Cooper, Allum, \& Nelmes, 2010). Orang tua dapat membatasi uang yang diberikan dan juga perlengkapan untuk bermain game online. Upaya ini dapat membatasi ruang gerak serta akses remaja terhadap permainan game online yang berlebihan.

\section{Penutup}

Perkembangan teknologi pada era digital ini tidak dapat dipungkiri sangat pesat adanya. Salah satu produk perkembangan teknologi yang saat ini digemari remaja adalah game online. Semestinya game online dimanfaatkan untuk hiburan tetapi yang terjadi game online dimainkan secara berlebihan, digunakan sebagai tempat untuk melarikan diri dari realitas kehidupan sehingga yang terjadi adalah kecanduan game online. Hal ini akan berakibat buruk terhadap berbagai aspek kehidupan remaja. Untuk itu, game online sebagai bentuk dari perkembangan teknologi perlu disikapi dengan bijak supaya tidak berdampak buruk bagi remaja. Dengan demikian remaja perlu diberikan upaya pecegahan terhadap kecanduan game online, sehingga diharapkan dapat terhindar dari kecanduan game online. Juga diharapkan pihak-pihak terkait dapat bersinergi dalam melakukan berbagai upaya yang telah disampaikan.

\section{Daftar Pustaka}

Adams, E. (2013). Fundamentals of game design (2nd ed). New York: New Riders Publishing.

Alexander, B. K. (2010). The globalization of addiction: A study in poverty of the spirit. New York: Oxford University Press.

Aziz, A. (2018). Kecanduan game online, 10 anak Banyumas alami gangguan mental. Diakses 7 September 2019, dari https://www.merdeka.com/peristiwa/ kecanduan-game-online-10-anak-dibanyumas-alami-gangguanmental.html

Baggio, S., Dupuis, M., Studer, J., Spilka, S., Daeppen, J. B., Simon, O., ... Gmel, G. (2016). Reframing video gaming and internet use addiction: Empirical cross-national comparison of heavy use over time and addiction scales among young users. Addiction, 111(3), 513-522. doi: 10.1111/add.13192

Blakely, G., Skirton, H., Cooper, S., Allum, P., \& Nelmes, P. (2010). Use of educational games in the health professions: A mixed-methods study of educators' perspectives in the UK. Nursing and Health Sciences, 12(1), 2732. doi: 10.1111/j.1442-2018.2009. 00479.x

Brand, J. E., Todhunter, S., \& Jervis, J. (2017). Digital Australia 2018 (DA18). http://www.igea.net/wpcontent/uploads/2017/07/DigitalAustralia-2018-DA18-Final-1.pdf.

Brunborg, G. S., Mentzoni, R. A., Molde, H., Myrseth, H., Skouverøe, K. J. M., Bjorvatn, B., \& Pallesen, S. (2011). The relationship between media use in the bedroom, sleep habits and symptoms of insomnia. Journal of Sleep Research, 20(4), 569-575. doi: 10.1111/j.1365$\underline{2869.2011 .00913 . x}$

Cha, S. S., \& Seo, B. K. (2018). Smartphone use and smartphone addiction in middle school students in Korea: 
Prevalence, social networking service and game use. Health Psychology Open, 5(1), 1-15. doi: 10.1177/2055102918 $\underline{755046}$

Chen, M. J., Grube, J. W., Nygaard, P., \& Miller, B. A. (2008). Identifying social mechanisms for the prevention of adolescent drinking and driving. Accident Analysis and Prevention, 40(2), 576-585. doi: 10.1016/j.aap.2007.08.013

Chen, Y. C., Chen, P. S., Hwang, J. J., Korba, L., Song, R., \& Yee, G. (2005). An analysis of online gaming crime characteristics. Internet Research, 15(3), 246-261. doi: 10.1108/1066224 $\underline{0510602672}$

Chou, C., Condron, L., \& Belland, J. C. (2005). A review of the research on Internet addiction. Educational Psychology Review, 17(4), 363-388. doi: 10.1007/s10648-005-8138-1

Dishion, T. J., Nelson, S. E., \& Kavanagh, K. (2003). The Family Check-Up with high-risk young adolescents: Preventing early-onset substance use by parent monitoring. Behavior Therapy, 34(4), 553-571. doi: 10.1016/S00057894(03)80035-7

Fossum, I. N., Nordnes, L. T., Storemark, S. S., Bjorvatn, B., \& Pallesen, S. (2014). The association between use of electronic media in bed before going to sleep and insomnia symptoms, daytime sleepiness, morningness and chronotype. Behavioral Sleep Medicine, 12(5), 343-357. doi: 10.1080/ $\underline{15402002.2013 .819468}$

Gentile, D. A., Bailey, K., Bavalier, D., Brockmyer, J. F., Cash, H., Coyne, S. M., ... Young, K. S. (2017). Internet gaming disorder in children and adolescents. Pediatrics, 140(2), S81-S85. Retrieved from \%3CGo\%0Ato

Ghuman, D., \& Griffiths, M. D. (2012). A cross-genre study of online gaming: Player demographics, motivation for play and social interactions among players. International Journal of Cyber Behavior, Psychology and Learning, 2(1), 13-29.

Griffin, K. W., \& Botvin, G. J. (2010). Evidence-based intervention for preventing substance use disorders in adolescents. Child and Adolescent Psychiatric Clinics, 19(3), 505-526. doi: 10.1016/j.chc.2010.03.005.

Haug, S., Castro, R. P., Kwon, M., Filler, A., Kowatsch, T., \& Schaub, M. P. (2015). Smartphone use and smartphone addiction among young people in Switzerland. Journal of Behavioral Addictions, 4(4), 299-307. doi: $10.1556 /$ 2006.4.2015.037

Hurlock, E. B. (2010). Psikologi perkembangan: Suatu pendekatan sepanjang rentang kehidupan (Alih Bahasa Istiwidayanti) (Edisi Kelima). Jakarta: Erlangga.

Hussain, Z., \& Griffiths, M. D. (2009). Excessive use of massively multiplayer online role-playing games: A pilot study. International Journal of Mental Health and Addiction, 7(2), 563571. doi: $10.1007 /$ s11469-009-9202-8

Hussain, Z., Griffiths, M. D., \& Baguley, T. S. (2012). Online gaming addiction: Classification, prediction and associated risk factors. Addiction Research and Theory, 20(5), 359-371. doi: $10.3109 / 16066359.2011 .640442$

Jannah, N., Mudjiran, M., \& Nirwana, H. (2015). Hubungan kecanduan game dengan motivasi belajar siswa dan implikasinya terhadap Bimbingan dan Konseling. Konselor, 4(4), 200-207. doi: $\underline{10.24036 / 02015446473-0-00}$

Jap, T., Tiatri, S., Jaya, E. S., \& Suteja, M. S. (2013). The development of Indonesian online game addiction questionnaire. 
PLoS ONE, 8(4), 4-8. doi: 10.1371/ journal.pone.0061098

Jiang, Q. (2014). Internet addiction among young people in China: Internet connectedness, online gaming and academic performance decrement. Internet Research, 24(1), 2-20. doi: 10.1108/IntR-01-2013-0004

Jordan, C. J., \& Andersen, S. L. (2016). Sensitive periods of substance abuse: Early risk for the transition to dependence. Developmental Cognitive Neuroscience, 25(10), 29-44. doi: 10.1016/j.den.2016.10.004

Kardefelt-Winther, D. (2017). Conceptualizing internet use disorders: Addiction or coping process? Psychiatry and Clinical Neurosciences, 71(7), 459-466.

Kiesner, J., Dishion, T. J., Poulin, F., \& Pastore, M. (2009). Temporal dynamics linking aspect of parental monitoring with early adolescent antisocial behavior. Social Development, 18(4), 765-784. doi: 10.1038/jid.2014.371

King, D. L., \& Delfabbro, P. H. (2018). Internet gaming disorder: Theory, assessment, treatment and prevention. New York: Academic Press.

King, D. L., Delfabbro, P. H., Zwaans, T., \& Kaptsis, D. (2014). Sleep interference effects of pathological electronic media use during adolescence. International Journal of Mental Health and Addiction, 12(1), 21-35. doi: 10.1007/s11469-0139461-2

Király, O., Griffiths, M. D., Urbán, R., Farkas, J., Kökönyei, G., Elekes, Z., ... Demetrovics, Z. (2014). Problematic internet use and problematic online gaming are not the same: Findings from a large nationally representative adolescent sample. Cyberpsychology, Behavior and Social Networking, 17(12),
749-754. doi: $\underline{\text { 10.1089/cyber.2014.0475 }}$

Kiraly, O., Nagygyörgy, K., Griffiths, M. D., \& Demetrovics, Z. (2014). Problematic online gaming. In K. P. Rosenberg \& L. C. Feder (Eds.), Behavioral addictions: Criteria, evidence and treatment (pp. 61-97). London, Inggris: Academic Press.

Kuss, D. J., van Rooij, A. J., Shorter, G. W., Griffiths, M. D., \& van de Mheen, D. (2013). Internet addiction in adolescents: Prevalence and risk factors. Computers in Human Behavior, 29(5), 1987-1996.

Kwon, J. H., Chung, C. S., \& Lee, J. (2011). The effects of escape from self and interpersonal relationship on the pathological use of internet games. Community Mental Health Journal, 47(1), 113-121. doi: 10.1007/s10597-009-92361

Lee, I., Yu, C. Y., \& Lin, H. (2007). Leaving a never ending game: Quitting MMORPGs and online gaming addiction. Proceedings of DiGRA Conference, 211-217.

Li, S., Jin, X., Wu, S., Jiang, F., Yan, C., \& Shen, X. (2007). The impact of media use on sleep patterns and sleep disorders among school-aged children in China. Sleep, 30(3), 361-367. Retrieved from http://www.ncbi.nlm.nih.gov/pubmed $/ 17425233$

Loke, A. Y., \& Wong, Y. P. I. (2010). Smoking among young children in Hong Kong: Influence of parental smoking. Journal of Advanced Nursing, 66(12), 2659-2670. doi: 10.1111/j.13652648.2010.05419.x

Männikkö, N., Billieux, J., \& Kääriäinen, M. (2015). Problematic digital gaming behavior and its relation to the psychological, social and physical 
health of Finnish adolescents and young adults. Journal of Behavioral Addictions, 4(4), 281-288. doi: 10. $\underline{1556 / 2006.4 .2015 .040}$

Marcovitz, H. (2012). Online gaming and entertainment. San Diego, CA: Reference Point Press.

Mogro-Wilson, C. (2008). The influence of parental warmth and control on Latino adolescent alcohol use. Hispanic Journal of Behavioral Sciences, 30(1), 89105. doi: $10.1177 / 0739986307310881$

Novrialdy, E., Nirwana, H., \& Ahmad, R. (2019). High school students understanding of the risks of online game addiction. Journal of Educational and Learning Studies, 2(2), 113-119.

O'Connell, M. E., Boat, T., \& Warner, K. E. (2009). Preventing mental, emotional and behavioral disorders among young people: Progress and possibilities. Washington DC: The National Academies Press.

Oblinger, D., \& Oblinger, J. L. (2005). Is it age or IT: First step toward understanding the net generation. In Diana Oblinger \& J. L. Oblinger (Eds.), Educating the net generation. Washington D.C.: Educause.

Oka, Y., Suzuki, S., \& Inoue, Y. (2008). Bedtime activities, sleep environment and sleep/wake patterns of Japanese elementary school children. Behavioral Sleep Medicine, 6(4), 220-233. doi: $\underline{10.1080 / 15402000802371338}$

Peele, S. (2004). Seven tools to beat addiction. New York: Harmony.

Petrides, K. V., \& Furnham, A. (2000). On the dimensional structure of emotional intelligence. Personality and Individual Differences, 29(2), 313-320. Retrieved from www.elsevier.com/locate/paid

Punamäki, R. L., Wallenius, M., Nygård,
C. H., Saarni, L., \& Rimpelä, A. (2007). Use of information and communication technology (ICT) and perceived health in adolescence: The role of sleeping habits and waking-time tiredness. Journal of Adolescence, 30(4), 569-585. doi: 10.1016/j.adolescence. $\underline{2006.07 .004}$

Rania, D. (2018). 7 kematian tragis gara-gara kecanduan game online. Mirisnya kejadian seperti ini makin sering terjadi. Diakses 7 September 2019, dari https://www.hipwee.com/feature/7kematian-tragis-gara-gara-kecanduangame-mirisnya-kejadian-seperti-inimakin-sering-terjadi/

Romano, J. L., \& Hage, S. M. (2000). Prevention and counseling psychology: Revitalizing commitments for the 21st century. The Counseling Psychologist, 28(6), 733-763.

Rudhiati, F., Apriany, D., \& Hardianti, N. (2015). Hubungan durasi bermain video game dengan ketajaman penglihatan anak usia sekolah. Skolastik Keperawatan, 1(2), 12-17.

Russoniello, C. V., O’Brien, K., \& Parks, J. M. (2009). The effectiveness of casual video games in improving mood and decreasing stress. Journal of Cyber Therapy \& Rehabilitation, 2(1), 53-66.

Sandy, T. A., \& Hidayat, W. N. (2019). Game mobile learning. Malang: Multimedia Edukasi.

Santrock, J. W. (2007). Remaja. Jakarta: Erlangga.

Shochat, T., Flint-Bretler, O., \& Tzischinsky, O. (2010). Sleep patterns, electronic media exposure and daytime sleep-related behaviours among Israeli adolescents. Acta Paediatrica, 99(9), 1396-1400.

Smyth, J. M. (2007). Beyond self-selection in video game play: An experimental 
examination of the consequences of massively multiplayer online roleplaying game play. Cyberpsychology and Behavior, 10(5), 717-721. doi: $\underline{10.1089 / \mathrm{cpb} .2007 .9963}$

Strittmatter, E., Kaess, M., Parzer, P., Fischer, G., Carli, V., Hoven, C. W., ... Wasserman, D. (2015). Pathological internet use among adolescents: Comparing gamers and non-gamers. Psychiatry Research, 228(1), 128-135. doi: 10.1016/j.psychres.2015.04.029

Taylor, S., \& Todd, P. A. (1995). Understanding information technology usage: A test of competing models. Information System Research, 6(2), 144-176.

Tsitsika, A., Janikian, M., Schoenmakers, T. M., Tzavela, E. C., Ólafsson, K., Wójcik, S., ... Richardson, C. (2014). Internet addictive behavior in adolescence: A cross-sectional study in seven European countries. Cyberpsychology, Behavior and Social Networking, 17(8), 528-535. doi: 10.1089/cyber. 2013.0382

van Den Eijnden, R. J. J. M., Spijkerman, R., Vermulst, A. A., van Rooij, T. J., \& Engels, R. C. M. E. (2010). Compulsive internet use among adolescents: Bidirectional parent-child relationships. Journal of Abnormal Child Psycho$\log y, 38(1), 77-89$. doi: 10.1007/s10802$\underline{009-9347-8}$

van Rooij, A. J., Schoenmakers, T. M., Vermulst, A. A., van den Eijnden, R. J. J. M., \& van de Mheen, D. (2011). Online video game addiction: Identification of addicted adolescent gamers. Addiction, 106(1), 205-212. doi: 10.1111/j.1360-0443.2010.03104.x
Wang, C. W., Chan, C. L. W., Mak, K. K., Ho, S. Y., Wong, P. W. C., \& Ho, R. T. H. (2014). Prevalence and correlates of video and internet gaming addiction among Hong Kong adolescents: A pilot study. The Scientific World Journal, 14(8), 1-9. doi: $\underline{10.1155 / 2014 / 874648}$

Wells, J., Barlow, J., \& Stewart-Brown, S. (2003). A systematic review of universal approaches to mental health promotion in schools. Health Education, 103(4), 197-220. doi: 10.1108/0965428 $\underline{0310485546}$

World Health Organization. (2018). Gaming disorder. Diakses 7 September 2019, dari https://www.who.int/ features/qa/gaming-disorder/en/

Williams, D. (2006). Groups and goblins: The social and covoc impact of an online game. Journal of Broadcasting $\mathcal{E}$ Electronic Media, 50(4), 651-670. doi: 10.1207/s15506878jobem5004_5

Xu, Z., Turel, O., \& Yuan, Y. (2012). Online game addiction among adolescents: Motivation and prevention factors. European Journal of Information Systems, 21(3), 321-340. doi: 10.1057/ejis.2011.56

Xu, Z., \& Yuan, Y. (2008). The impact of motivation and prevention factors on game addiction. Proceeding of SIGHCI.

Young, K. S. (1998). Internet addiction: The emergence of a new clinical disorder. CyberPsychology \& Behavior, 1(3), 237244. doi: $\underline{10.1089 / \mathrm{cpb} .1998 .1 .237}$

Zhou, Z., Yuan, G., \& Yao, J. (2012). Cognitive biases toward internet game-related pictures and executive deficits in individuals with an internet game addiction. PLoS ONE, 7(11), e48961. doi: 10.1371/journal.pone. $\underline{0048961}$ 